\title{
Dental Material
}

National Cancer Institute

\section{Source}

National Cancer Institute. Dental Material. NCI Thesaurus. Code C42634.

Substances that are used in the clinical practice of dentistry for the production of fillings, restorations, impressions, and prostheses. 